\title{
Fabrication and Evaluation of Atmospheric Corrosion Monitoring (ACM) Sensor of Fe-Cu Galvanic Couple
}

\author{
RabinaNuchhe Pradhan ${ }^{1}$, Brahamdeo Yadav ${ }^{3}$, Prakash Chandra Lama ${ }^{1}$, Suman Shrestha ${ }^{1}$, Shova \\ Neupane ${ }^{I}$, Dipak Kumar Gupta ${ }^{1}$ and Amar Prasad Yadav ${ }^{2 *}$ \\ ${ }^{I}$ Department of Chemistry, Tri-Chandra Multiple Campus, Bhatnagar, Kathmandu, Nepal \\ ${ }^{2}$ Central Department of Chemistry, Tribhuvan University, Kirtipur, Kathmandu, Nepal \\ ${ }^{3}$ Depart of Chemistry, RR Multiple Campus, Tribhuvan University, Janakpur, Nepal \\ Email: amar2y@yahoo.com
}

\begin{abstract}
Atmospheric Corrosion Monitoring(ACM) Sensor of Fe-Cu galvanic couple was fabricated and was used to estimate corrosion of commercial iron in bulk solutions ( $\mathrm{NaCl}, \mathrm{Na}_{2} \mathrm{SO}_{4}$ and their mixture), thin layer of electrolyte $(0.1 \mathrm{MNaCl})$ and upon field exposure. Thin layer of electrolyte was maintained using myler sheet of $100 \mu$ and $500 \mu$. The corrosion of commercial iron was found to be highest in thin layer of electrolyte of thickness $100 \mu$. Field exposure test revealed that commercial iron suffered severe corrosion at night than during day light.
\end{abstract}

Keywords: ACM Sensor, thin layer electrolyte, myler sheet, corrosion

\section{Introduction}

Atmospheric corrosion and its monitoring has always been a serious topics through years. It is because the damage caused by it is much more than just the loss of infrastructures but it also costs the life of beings. The vital factor in atmospheric corrosion is the presence of moisture which get deposited as thin layer of electrolyte on metals ${ }^{1}$. So it's a challenge to monitor atmospheric corrosion as it requires electrochemical set up to be used in very thin layer of electrolyte yet there are various techniques to monitor $\mathrm{it}^{2,3}$. Various techniques includes weight loss method, polarization method, electrochemical impedance spectroscopy and through atmospheric corrosion monitoring sensor. Among which atmospheric corrosion monitoring through atmospheric corrosion monitoring Sensor is considered to be one of the major one ${ }^{3}$.

Atmospheric corrosion monitoring (ACM) sensor sample comprises couple of two metals. The metals whose corrosion rate is to be monitored is made anode and less electropositive metals is made cathode. The galvanic current, flown due to oxidation and reduction reaction on surface of sensor when deposited thin layer of electrolyte completes galvanic cell, is recorded by data logger which is later related with corrosion rate. Various types of ACM sensors have been developed, first being ACM sensor of Fe-Ag galvanic couple made in Japan ${ }^{4}$. ACM sensor of Zn- graphite developed by Tiajin University-Liceram Joint laboratory is of another types. It was used to analyze corrosion of zinc and factors responsible for its corrosion $^{5}$.

\footnotetext{
* Corresponding author
} 


\section{Experimental Mathods}

\section{Design of ACM Sensor (series Type)}

The iron and copper samples used in the fabrication of ACM Sensor were cut from commercial iron and copper sheets of different dimensions $(0.75 \mathrm{~mm} \times 11 \mathrm{~mm}$ and $0.25 \times 10 \mathrm{~mm})$. They were joined in series with separation of $50 \mu$ maintained with the help of myler sheet. The connection between each individual iron and copper sample was maintained using copper tape and silver paste. Copper wire was soldered with iron sample of one end and also with the copper sample of other end. Connection between each iron and copper sample was maintained using multimeter. The series was then embedded in epoxy resin and left for 24 hours for solidification.

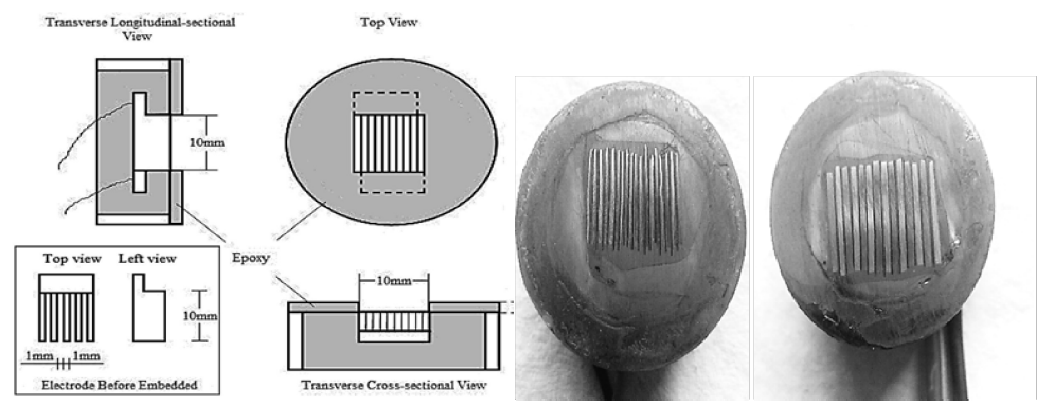

Figure 1: (A) Schematic representation of ACM (B) ACM Sensor

Thus fabricated ACM sensor of $\mathrm{Fe}-\mathrm{Cu}$ galvanic couple was used to estimate corrosion of commercial iron in bulk solution, thin layer of electrolyte of different thickness and upon field exposure.

\section{Lab Corrosion Test (Bulk solution, thin layer of electrolyte)}

For lab corrosion test, ACM Sensor was maintained at the base of the beaker to which solutions of different salts $\left(\mathrm{NaCl}, \mathrm{Na}_{2} \mathrm{SO}_{4}\right.$ and their mixture) was poured. Sensor was then connected to SACM $302 \mathrm{~B}$ (data logger) which stores galvanic current flowing on the surface of the sensor. This galvanic current recorded was related with the corrosion rate.

Thin layer of electrolyte was maintained using myler sheet of $100 \mu$ and $500 \mu$.The electrolyte used was $0.1 \mathrm{M} \mathrm{NaCL}$

\section{Field Exposure Test}

The fabricated ACM was mounted at angle of $45^{\circ}$ to the horizontal in front of Central Department of chemistry. The sensors were directly exposed to wind, rain, and solar radiation. The data was collected by SACM 302 B available at central department of chemistry every 10 minutes for 2 weeks. After the test, data were collected for analysis.

\section{Results and Discussion}

The galvanic current recorded by Syrinx SACM 302 B during immersion and exposure of both the sensors in bulk solution, under thin layer of electrolyte and outdoor environment was analyzed. The galvanic current recorded was divided by respective area of ACM Sensor A and B to calculate their respective current density. The graph was plotted to relate current density with time as shown in, figure 2,3 and 4 . 


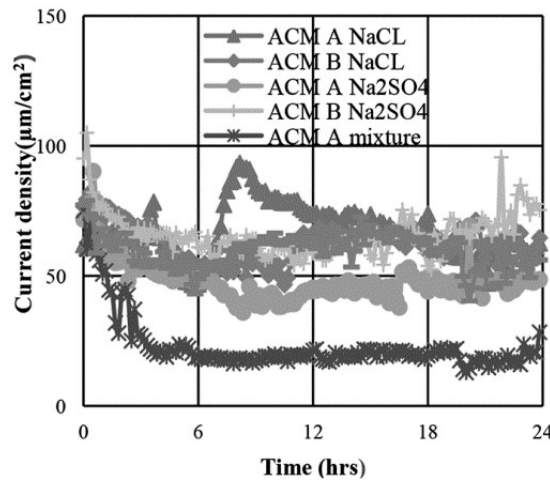

$0.0001 \mathrm{M}$

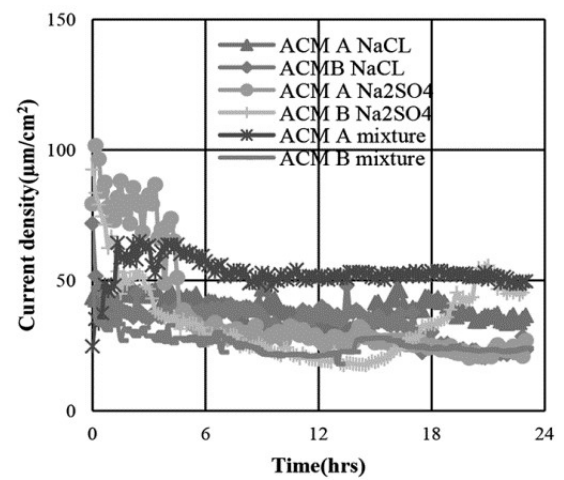

$0.1 \mathrm{M}$

Figure 2: Current density vs time plot of ACM Sensor $A$ and $B$ in different concentrationsof salt solutions ( $\mathrm{NaCL}$ and $\mathrm{Na}_{2} \mathrm{SO}_{4}$ ) and their mixture.

From fig 2, current density was found to increase in both the ACM Sensor samples (A and B) with the increase in the concentration of both the salt solutions and their mixtures from $0.0001 \mathrm{M}$ to $0.1 \mathrm{M}$. This is due to the lowering of $\mathrm{pH}$ of the salt solution, by ions, in contact with the ACM sensor which consequently, dissolves the oxide film on the iron surface to react with metallic iron and transports it into the solution

This can also be explained on the basis of the increase of the conductivity of corrosion cell which establish concentration cell potentials. The difference in salt concentration between highly contaminated areas an adjacent less contaminated areas creates a voltage which causes corrosion current to flow ${ }^{6}$. But case is opposite when ACM A sensor is immersed in $0.1 \mathrm{M}$ mixture. The rust formed during the process is of dark brown color which acted as a passivating layer which hinders access of anionsto anode surface, inhibiting metal dissolution reaction.

The morphology of both the ACM sensors depicts the extent of corrosion, with the increase in the concentration form $0.0001 \mathrm{M}$ to $0.1 \mathrm{M}$.

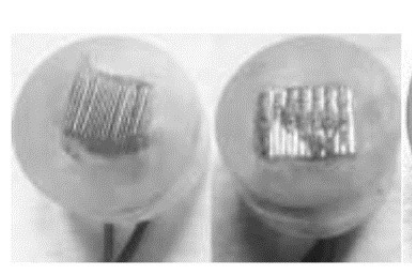

$0.0001 \mathrm{M} \mathrm{NaCL}$

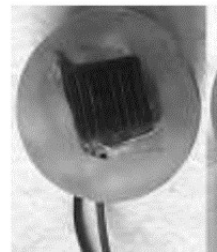

0. $1 \mathrm{M} \mathrm{NaCL}$

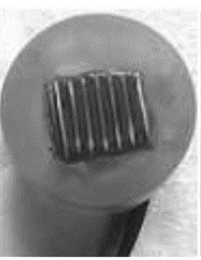

$0.0001 \mathrm{M} N a_{2} \mathrm{SO}_{4}$

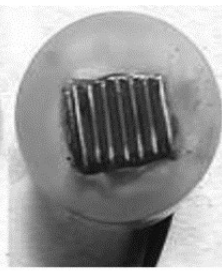

$0.0001 \mathrm{M}$ Mixture
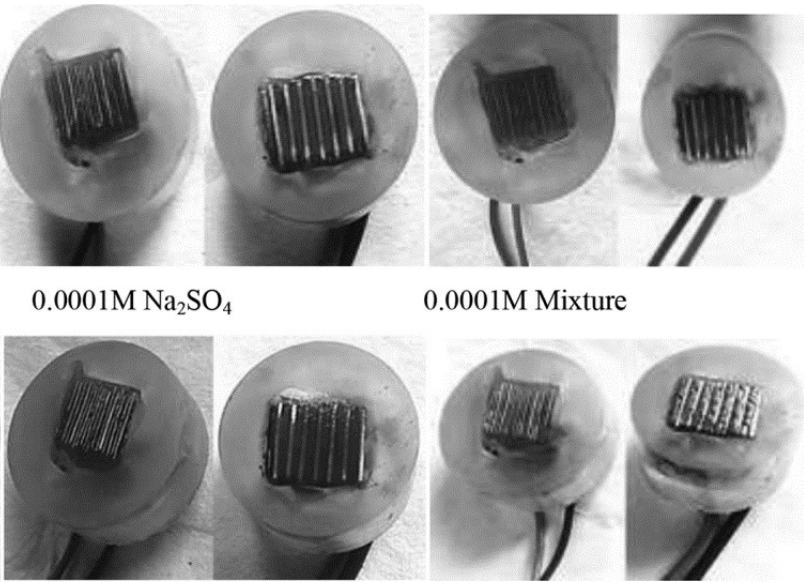

$0.1 \mathrm{M} \mathrm{Na}_{2} \mathrm{SO}_{4} 0.1$

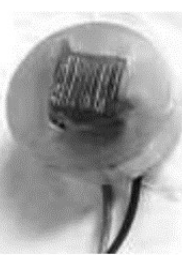

M Mixture

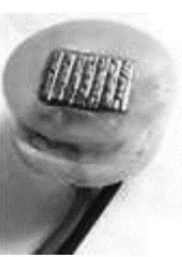

Figure 3: Pictorial view of sensor after immersion in different concentrations of salt solutions and their mixture. 
The galvanic current measured by Syrinx SACM 302 B under thin layer of electrolyte layer in both the ACM sensor was found to be much higher than in bulk solution of sodium chloride as well as in sodium sulphate solution as shown in fig 1.3. Current density in both the samples were calculated from values of galvanic current measured. This higher current density in thin layer of electrolyte is due to rapid diffusion of oxygen in thin layer than that in bulk solution. Moreover, diffusion in thin layer of electrolyte is two dimensional but that in case of bulk solution is one dimensional which results in the higher diffusion and concentration of oxygen facilitating corrosion process.

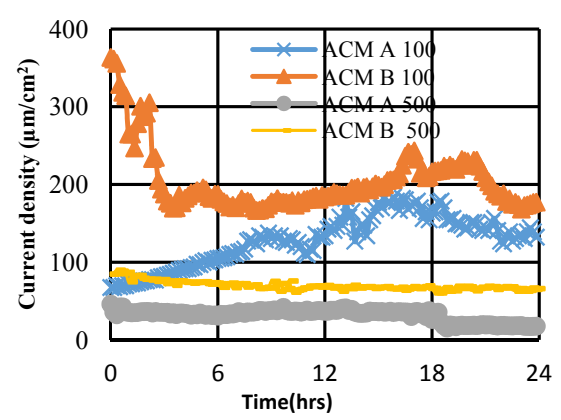

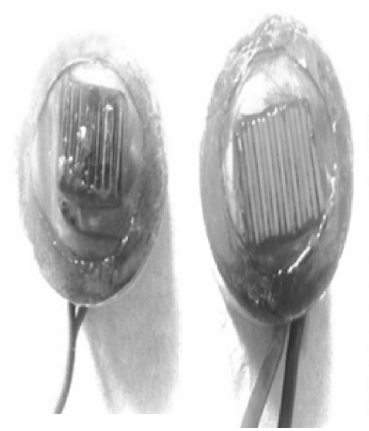

$500 \mu$ thickness
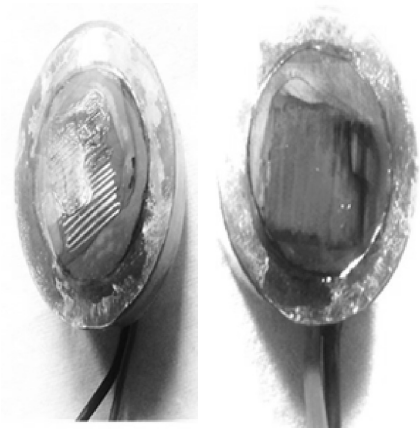

$100 \mu$ thicknes

Figure 4: Current density versus time plot of two

Sensors(A and B) under thin film of electrolye Figure 5: Pictorial view of sensor under thin film ofelectrolyte

\section{Field Exposure Test}

The galvanic current recorded by Syrinx SACM 302 B during the exposure of both the sensors in outdoor environment at Central Department of Chemistry for two weeks was analyzed.The graph was plotted to relate current density with time as shown in Fig.1.5
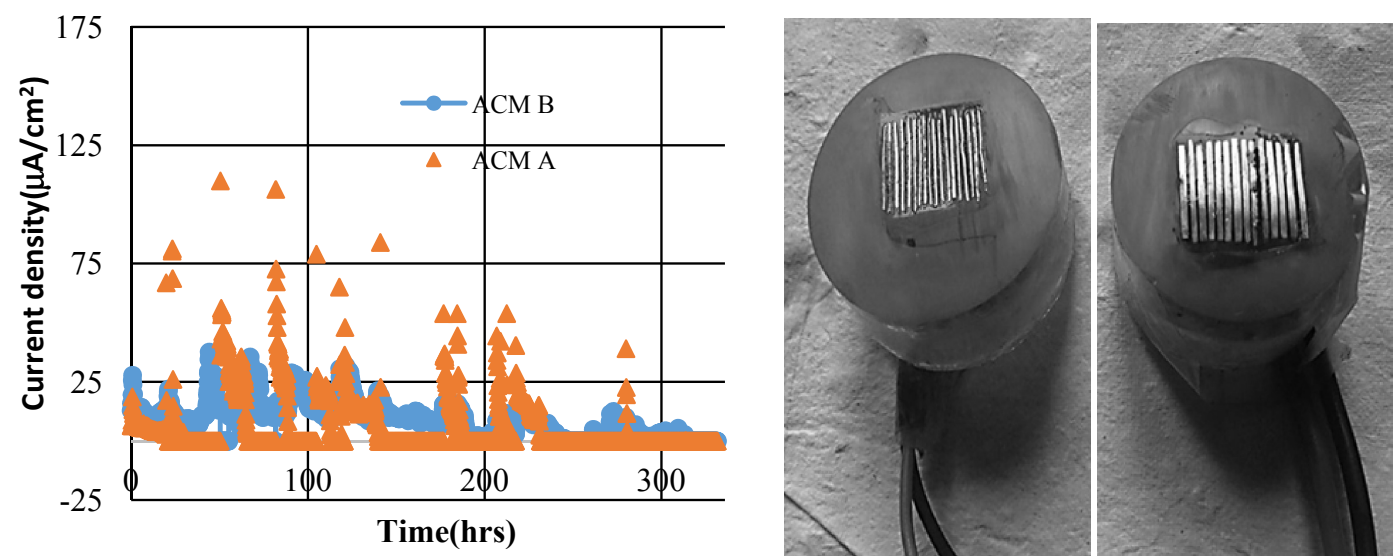

Figure 5 Current density versus time plot of two ACM sensors Figure 6 Morphology of ACM Sensors after 2 exposed outside Central Department of Chemistry for 2 weeks. weeks of field exposure 


\section{J. Nepal Chem. Soc., Vol. 36, 2017}

The above graph shows the response of both ACM sensors with the change in the environmental factors. It was seen that current density in both the sample is much higher in night than during day time. This increase in current density during night is attributed to dew condensation ${ }^{7}$.

At night when relative humidity reaches approximately to $100 \%$ and temperature decreases, ACM sensor gave low solution resistance which in turn increases the conductance. This indicates corrosion process occurring on the surface of both the ACM sensor is due to the wetness of the surface i.e dew condensation. On the other hand when relative humidity decrease and temperature increases during day time, conductance of the solution is decreased due to increase in the resistance of solution. This is why corrosion is suppressed because of drying of surface of ACM sensors during day time.

But during the rainy time i.e third and fifth day of exposure of sensor, both the ACM sensor experienced high corrosion even during day time.

\section{Conclusions}

The corrosion of commercial iron was evaluated using fabricated Atmospheric Corrosion Monitoring (ACM) Sensor of $\mathrm{Fe}-\mathrm{Cu}$ galvanic couple. It was found that iron suffered severe corrosion when it was under electrolyte layer thickness of $100 \mu$ than electrolyte thickness of $500 \mu$ and in bulk solution of salt solutions $\left(\mathrm{NaCL}, \mathrm{Na}_{2} \mathrm{SO}_{4}\right.$ ) and their mixtures of different concentrations.

Upon field exposure of ACM Sensor, it is observed that during night time, corrosion is heavier than during daylight.

\section{References}

1. C. Leygraf, I. O. Walinder, J. Tidblad, T. Graedal, "Atmospheric Corrosion" second edition, A John Wiley \& Sons, Inc, publication, Canada, 2016

2. A. P. Yadav, Differential Pressure Transducer for monitoring of iron, Int J ApplSciBiotechnol, 2(1): 109-111

3. F. Kuang, J. Zhang C. , Zou, Y. Wang, S. Zhan, H. Xu, Electrochemical Methods for Corrosion Monitoring: A Survey of Recent Patents, Corrosion Science, 2010, 2, 34-39

4. S E. Tsujikawa, T. Shinohara, S. Motoda, Atmospheric Corrosion Monitoring by ACM Type Corrosion Sensor

5. X. Wang, X. Li, X Tian, Influence of Temperature and Relative Humidity on the Atmospheric Corrosion of Zinc in Field Exposures and Laboratory Environments by Atmospheric Corrosion Monitor, Electrochem. Sci., 2015, 10, 8361 - 8373.

6. S. E. Traubenberg, R. T. Foley, The Influence of Chloride and Sulfate Ions on the Corrosion of Iron in Sulfuric Acid, The Electrochemical Society, 1971, 118 (7), 1066-1070

7. M. Stratmann, H. Streckel, The Investigation of the Corrosion of Metal Surfaces, Covered with Thin Electrolyte Layers - A New Experimental Technique, 1988, 92(11), 1244-1250. 